\title{
FACTORS AFFECTING COOPERATION AMONG PHYSICIANS IN SHARING INFORMATION WITHIN THE HOSPITAL ENVIRONMENT: A STUDY OF TWO HOSPITALS
}

\author{
${ }^{1}$ Nawzat Sadiq Ahmed and ${ }^{2}$ Norizan Mohd Yasin \\ ${ }^{1}$ Department of Computer Science, Faculty of Science, University of Zakho, Zakho, Kurdistan Region, Iraq \\ ${ }^{2}$ Department of Information System, \\ Faculty of Computer Science and Information Technology, University of Malaya, 50603 Kuala Lumpur, Malaysia
}

Received 2013-06-16; Revised 2014-01-13; Accepted 2014-01-15

\begin{abstract}
Healthcare Information Systems (HISs) in hospitals have become an influential factor to provide cooperation among physicians in sharing healthcare information. Many cooperative HIS models were proposed. However, they focused on management of the patients' information and do not address the issue of improving the physicians' skills due to many factors. In this study, a mixed data collection approach is used first to determine the current levels of cooperation among physicians with regard to the sharing of information and skills in the patient treatment within selected hospitals in Kurdistan region of Iraq. The second, it is first used to determine factors affecting such cooperation and second to determine how the activities of Research and Development (R\&D) units affect this cooperation. The results of this study showed that the cooperation among physicians in sharing information and skills is poor due to the six important factors. The study also founded that there is positive relation between R\&D unit activities and cooperation among physicians in sharing patient information and their skills. The study findings provided that the development of cooperative HISs environment should be adapted based on an open, autonomic, flexible and cooperative model to support exchange of productive information among physicians in real time in order to improve their skills by acquiring new knowledge from each other within same and between different hospitals.
\end{abstract}

Keywords: Cooperation, Healthcare Information System (HIS), Factors, Flexible and Cooperative Model

\section{INTRODUCTION}

Cooperation among physicians in sharing information has become an important issue in healthcare systems to provide a good quality care for patients. Healthcare systems include individual centers supported by autonomous Healthcare Information Systems (HISs), such as hospitals (Fedele, 1995). HISs in hospitals accumulate electronic information, such as patient records, doctor schedules and others (Al-Khawlani, 2009). HISs play an important role in providing patient information to physicians, nurses and administrative staff, thus HISs can be a significant factor in developing cooperation among physicians with regard to sharing healthcare information (Yang et al., 2010; 2011). The healthcare system has used many types of cooperation among physicians and HISs in hospitals have developed to allow easy exchange of up-to-date patient information among medical staff in real-time. Hence, there is an urgent need for integrated multi-HIS to provide an effective cooperative HISs environment (Yang et al., 2010). There are many cooperative HIS models (Aknine and Aknine, 1999); but, these models are developed as warehouses containing patient information (Skilton et al., 2008) and they are limited by their capability to react to system changes, especially in the circulation and updating of new data, knowledge and information (Kirikova, 2009). Over time, new requirements of cooperation among physicians will emerge to design cooperative HISs environment, where they need to

Corresponding Author: Nawzat Sadiq Ahmed, Department of Computer Science, Faculty of Science, University of Zakho, Zakho, Kurdistan Region, Iraq 
maximize information sharing in order to provide accurate information in an appropriate and timely manner to support physicians' decisions, hence producing better healthcare services (Skilton et al., 2007). Thus, the cooperation among physicians becomes an important issue in a developing cooperative HISs environment; but such an environment needs to overcome many challenges, such as the difficulty of managing and controlling huge data in complex healthcare systems; the maintenance autonomy for each site; flexibility approach for cooperative requirement in accommodating the dynamic nature of health services; and acquiring real-time new knowledge from external environments to produce a multi-expert care team. These challenges are prominent factors affecting cooperation among physicians in sharing healthcare information (Dembo, 2010; Skilton et al., 2007; 2008).

In many developing countries, HISs are separate from each other and mostly using manual system. This is the same for most Iraqi hospitals (Ali et al., 2011). The disintegrated HISs and manual system lead to lack of information sharing and cooperation among medical staff, impeding optimal usage of healthcare resources and delaying findings of new diagnostics and therapeutics as large amount of data are difficult to manage and control in a paper environment. In such case, it is difficult to distribute information regarding new discoveries among hospitals; but these new information are important to enhance both physicians' knowledge, skills and improving healthcare services (Dembo, 2010). New knowledge is not acquired in real-time in disintegrated of HISs and manual systems. Cooperation by communicating sharing of skills among physicians improves their skills in providing patient treatment for higher-quality care to patients (Chiasson et al., 2007; Dembo, 2010; Kannampallil et al., 2011). Physicians working individually are not able to improve their skills in diagnosing patient's disease and providing therapy in healthcare centre as working independently lead to insufficient experience (Burnham et al., 2012; Mun et al., 2009; Weir et al., 2011).

Research and Development (R\&D) unit is an important unit as there are many experiments and activities that lead to new knowledge and information; hence, it play an important role to improve cooperation among staff and enhances services by exchanging operation activities among staff (Chiesa, 1996).

According to the cooperation among physicians in sharing information within the hospital environment, there are many factors that lead to lack of access to relevant and up-to-date information among physicians
(Skilton et al., 2008; Xiao et al., 2010), that may lead to poor cooperation activity (Reddy et al., 2011).

According to the World Health Organization (WHO) and the Ministry of Health (MOH) of Iraq, the lack of computerized HIS in most Iraqi hospitals leads to poor data analysis and information flow within the hospital environment. Also, the healthcare system in Iraq is still centralized and hospital-based. This situation happened because the country faced enormous problems, such as poor security and the effects of war (WHO, 2006). After the 2003 invasion on Iraq, many doctors left the country because of the deterioration of healthcare services, shortage of medical staff and violence against doctors (including several assassinations). Not surprisingly, current medical skills in Iraqi hospitals are very poor (Burnham et al., 2012). In Iraqi hospitals, physicians work individually and not cooperatively as a result of time factor. Physicians also generally lack cooperation in sharing patient information and skills in their hospital and with other hospitals. These situations lead to inadequate access to primary care, low quality medical treatment level and physical facilities that require major repairs (Alwan, 2004; WHO, 2006). In particular, the Federal Region of Kurdistan in Iraq recently interest in the development of healthcare facilities and safe movement between cities and moved to automate the healthcare systems of regional healthcare organizations, with the support of the regional ministry of health (Heshmati and Darwesh, 2007). In addition, the regional minister reported that "the new generation is born with many diseases including congenital heart disease which we don't know why and it may be associated with the long-term effects of chemical bombings in Kurdistan between 1987 and 1991" (Isa, 2008). The regional minister also added that heart disease is a major problem in Kurdistan region (KRG, 2007). Furthermore, skills and experiences of the local surgeons and cardiologists are lacking (Burnham et al., 2012; Custer, 2009). Therefore, the physicians in cardiac centers need to cooperate with other physicians to improve their skills and enhance their ability to provide excellent medical services to citizens (KRG, 2007).

This study follows a complementary mixed method to (1) determine the current levels of cooperation among physicians in sharing of information and skills in the patient treatment, (2) to determine factors affecting cooperation initiatives among physicians and (3) to determine how the activities of R\&D units affect such cooperation in two government hospitals in Kurdistan region of Iraq. Based on the aforementioned, the study aims to recommend an adequate cooperative HISs model to improve physicians' skills within the hospital environment. 


\section{RELATED WORK}

\subsection{Cooperation Among Physicians within the Hospital Environment}

The term "cooperation" in the field of healthcare is defined as the communication that occurs among healthcare practitioners when sharing information and skills in patient care (Gaboury et al., 2009; Scandurra et al., 2008; Weir et al., 2011). Several researchers call such exchange of information as "collaboration". In this study, the term "cooperation" is used. This section covers a number of relevant issues on cooperation among physicians from different centers or hospitals. It aims to discover the levels of cooperation among physicians in sharing information and the effect of this cooperation in patient outcomes. As noted in various studies, the nature of medical work in healthcare systems is cooperative among healthcare professionals (Chiasson et al., 2007; Kuziemsky and Varpio, 2011). Researchers have directed their attention to study the role of cooperation in healthcare and how to best support cooperation among the medical staff. Results show that poor technology systems may result in lack of cooperation among the medical staff (Reddy et al., 2011) and consequently, may harm patients (Weir et al., 2011). According to Reddy et al. (2011), an established cooperation among physicians and healthcare workers needs an appropriate communication system. The general model of collaboration in any system is illustrated in Fig. 1 (Abdullah et al., 2005).

Figure 1 shows that many types of collaboration exist, including face-to-face collaboration, which is a type of synchronous collaboration. Another type of collaboration is distributed synchronous collaboration, which uses video-conferencing and telemedicine systems (Hameed et al., 2008). In addition, there is asynchronous collaboration, in which hospital staff use Electronic Health Records (EHRs) as tools for communication (Collins et al., 2011). Finally, a distributed asynchronous collaboration is another type of collaboration wherein healthcare practitioners can cooperate with each other by sharing healthcare information and activities in different times and places. HIS is a type of asynchronous and distributed asynchronous collaboration. Such systems provide patient information to physicians, nurses and administrative staff about their work (Yang et al., 2011).

According to studies by Ali et al. (2011); Gaboury et al. (2009); Hameed et al. (2008); Mengiste (2010); Scandurra et al. (2008); VanVactor (2012) and Yang et al. (2010), many developing countries including Iraq still use manual and stand-alone systems in their hospitals. These studies also indicate that using manual and individual systems has led to insufficient cooperation among medical staff. Furthermore, many hospitals nowadays use both manual and computerized systems because of the complexity of healthcare system environments (Kumar et al., 2012). Therefore, such countries need to introduce information technologies and effective cooperation in their healthcare systems (Mengiste, 2010).

Ali et al. (2011) reviewed and assessed HIS in warstricken Iraq. Before 2003, Iraq was completely isolated from other countries around the world. After the 2003 invasion, healthcare services deteriorated and many doctors left Iraq. Public and private healthcare centers suffered and, consequently, so did effective cooperation within the healthcare systems.

According to Chiesa (1996), cooperation among decentralized R\&D units within the same firm has a positive effect on product outcomes. This effect is based on the fact that activities of $R \& D$ units in any setting play an important role in improving cooperation among staff and in enhancing services. In addition, Chiesa added that the tasks of R\&D units can be carried out by exchanging activities among staff within the same and with different units. Furthermore, the acquisition of new knowledge by the staff can be investigated through externalization of $R \& D$ activities by exchanging information among the staff using Webbased techniques (Chiesa et al., 2004). An article in the RCN (2004) also added that providing quality patient care depend on R\&D activities in healthcare systems. This claim means that lack of cooperative activities may lead to poor patient outcomes.

In Iraqi hospitals, the lack of cooperation among physicians in sharing information within same and between different hospitals exists due to mostly use manual systems (2011). Therefore, this study addresses such cooperation among physicians by using cooperative HISs.

\subsection{Cooperative HIS Models}

Cooperative HISs can improve patient treatment and provide up-to-date information allowing physicians of informed decisions (Ruxwana et al., 2010). There is a need for an integrated cooperative HIS environment because many HISs units are decentralized and autonomous (Yang et al., 2009).

Aknine and Aknine (1999) proposed a multi-agent cooperation model between hospital actors (i.e., doctors, nurses, analysts and others) to introduce the best services to accelerate patient treatment. However, this model focuses only on patient information aggregated in a centralized location. 


\begin{tabular}{|l|c|c|}
\hline \multicolumn{1}{|c|}{ Same time } & \multicolumn{1}{c|}{ Different time } \\
\cline { 2 - 3 } Same place & $\begin{array}{c}\text { Face-to-face collaboration } \\
\text { (Synchronous) }\end{array}$ & Asynchronous collaboration \\
\cline { 2 - 3 } Different place & $\begin{array}{c}\text { Distributed synchronous } \\
\text { collaboration }\end{array}$ & $\begin{array}{c}\text { Distributed asynchronous } \\
\text { collaboration }\end{array}$ \\
\hline
\end{tabular}

Fig. 1. Collaboration of working model

Skilton et al. (2007) proposed to a model that connect HISs based on virtual organizations with service-oriented architecture aims to increase flexibility and extensibility of the system but this proposed model merely focuses on viewing patient information in a centralized location. Ruxwana et al. (2010) studied five rural healthcare centers on how Information Communication Technologies (ICTs) can be used more effectively to improve the health system based on the participant requirements looking at ICT solutions in achieving cooperation among medical staff sharing patient information in these hospitals. Lu (2005) proposed the use of Computer Supported Cooperative Work (CSCW) technology focusing on factors including cooperation activities initiatives of the physicians; physicians collaboration and information sharing in patient treatment and collaboration in resources and tasks scheduling. National Immunization Information System (NIIS) model proposed by Chiu et al. (2007) included central database to investigate aggregating data from different databases that lead to many benefits of providing information in integrated form and speedily. Kuziemsky and Varpio (2011) proposed an awareness model to enhance the ability to design HISs to support asynchronous inter-professional collaborative care delivery. Reddy et al. (2011) found that most of earlier cooperative HISs models focus on sharing of patient information among physicians.

In particular, the $\mathrm{MOH}$ of Iraq started using information technologies in healthcare systems. However, the $\mathrm{MOH}$ faced problems during the implementation of these techniques. The main reason for such difficulties was that healthcare systems in Iraq were hospital-based and centralized (WHO, 2006). In addition, physicians were working individually and not cooperatively because doctor-topatient ratio worsened after the war, thus leading to poor healthcare services (Alwan, 2004).
Based on previous studies, most of the earlier researches focused on the patient information and information about providing better services to patients such as patients follow up; however, none of these researches look at developing real-time cooperative HISs model to improve physicians' skills. Challenges in doing so is due to factors: (1) each medical units wish to maintain autonomy in cooperative HISs environment, (2) a flexible cooperative approach is not the norm in sharing information in such an environment evidence from many models that was developed as centralized database to share patient information among units (Skilton et al., 2007; 2008; Yang et al., 2010).

\section{RESEARCH APPROACH}

To achieve the objectives of the current study, the researcher adopted the mixed methods approach. This method included both qualitative and quantitative instruments of collecting data. The use of both the instruments was necessary to encompass the different aspects of cooperation among physicians in sharing information and skills in the patient treatment within the hospital environment. According to Curry et al. (2009), the combination of both qualitative and quantitative data collection, as a mixed methods approach, can be useful, especially in the healthcare services research. The philosophy behind this approach is that the systematic synthesis of different methods will compensate for some of the inherent weaknesses of the individual methods when applied alone (Curry et al., 2009; Kopala and Suzuki, 1999).

In this research as case study, qualitative and quantitative data collection instruments included questionnaires and semi-structured interviews. Additionally, to provide a more complete and multidimensional understanding of the issues, Morgan 
(1998) priority-sequence model (QUANT $\rightarrow$ qual) as adapted from Morse (1991) was employed as a complementary methodology design. Such a model was used in the data collection procedure, data analysis and discussion of findings.

To compile, design and develop data collection instruments of this study, a careful process of collecting and gathering the required information was carried out in a number of ways. On the one hand, the research instruments were constructed after a thorough review of the available published literature, such as Samuel (2009); Shahmoradi et al. (2007); Reddy and Jansen (2008) and Al-Tae (2009), consultation with local experienced physicians and reflection upon the researcher's knowledge and professional experience. On the other hand, the researcher conducted a thorough literature review to familiarize himself with the conceptual foundations. Unfortunately, most of the prior researchers in the literature review, such as Collins et al. (2011); Gotoh et al. (2005); Li and Yao (2006); Reddy and Jansen (2008); Sadreddini (2003); Yang et al. (2009; 2008), addressed the issue of cooperation among physicians in sharing information using qualitative instruments. This indicated that no previously tested questionnaire was available for this research study; therefore, the researcher was required to develop and validate the questionnaires before their use. Furthermore, the research instruments were then tested to evaluate their validity and reliability through expert validation and face validation followed by a pilot test (Best and Kahn, 2006; Bryman, 2008; Odeh, 1999).

Initially, ethical approval from the Research Ethics Committee of Health of Directorate General of Health, Duhok Governorate, Ministry of Health, Kurdistan region of Iraq, was obtained before any information was gathered from any of the hospitals selected as the case study. Through a written letter and personal visits, the researcher informed the health directors and hospital managers about the upcoming study. Official permission was obtained from the health directors and the hospital managers.

\subsection{Research Instruments}

The questionnaire instrument that used in this research has five sections: (1) demographic, (2) background Information, (3) professional cooperation among physicians, (4) the work of research and development (R\&D) unit in the hospital and (5) suggestions. For the pilot test, the questionnaires were distributed among nine physicians in the hospital from the proposed study population and show a high internal reliability value 0.83 for section 3 and 0.85 for section 4 of the questionnaire. The values were higher than the reliability indicator provided by (Nunnally, 1978). In most cases, the researcher handed the questionnaire directly to the participants.

Data analysis of the questionnaires was performed using the Statistical Package for the Social Sciences (SPSS). Likert scales, descriptive statistics (e.g., percentage, means and standard deviations) were used to describe the basic features of collected data. A simple regression analysis was conducted to identify the effectiveness of R\&D unit activities on professional cooperation among physicians in the hospital environment. Qualitative data from open-ended questions in the suggestions section of the questionnaire were analyzed using narrative analysis as content analysis process (Suter, 2011). In such process, main and emerging ideas were recognized in several readings of the data. Certain words and phrases that repeatedly appeared emerged from the data.

The interview guide was developed set of interview questions. These questions were developed based on the objectives of the study. The open-ended questions used during the interview process were based on recommendations from existing literature, anecdotal information and conversations with the researcher's expert cardiology colleagues (Bryman, 2008). Overall, 25 questions were asked during the interviews and each interview session took approximately one to two hours. The Kurdish, Arabic and English languages were used in the interviews. The interviews continued until data saturation was achieved (i.e., no new opinions were raised) (Bryman, 2008). With the permission of the physicians, data were recorded, written and summarized. These data were then translated into English, transcribed and analyzed based on themes (Miles and Huberman, 1994).

\subsection{Participants}

In this study, the samples of participants consisted of physicians, the selection of whom was based on purposive sampling that involves selecting particular units or cases (Teddlie and $\mathrm{Yu}, 2007)$. According to Leary (2011), in the purposive sampling, researchers can decide which participants include in the sample. As mentioned, a sample of physicians from two government hospitals (Hospital A and Hospital B) in the federal region of Kurdistan, Iraq was selected as a case study. In addition, the selection of the sample focused on physicians who work in care units related to the cardiac centre in each hospital. Table 1 illustrates their locations. 
The aforementioned hospitals (Table 1) were selected as subjects of this study for several reasons. First, deterioration in services and unsafe movement between cities have occurred following the 2003 invasion of Iraq (Ali et al., 2011; Burnham et al., 2012). Second, interest in the development of healthcare facilities and safe movement between cities in the federal region of Kurdistan is considerable. Third, difficulty exists in connecting government and private hospitals because health services in government hospitals are provided free to the country's residents (Heshmati and Darwesh, 2007). Fourth, selected hospitals have cardiac centers because heart disease is a major health problem in Kurdistan region, as the Ministry of Health in this region noted (KRG, 2007). However, these cardiac centers are limited in number and became available in Kurdistan region after 2007 (KRG, 2007). Furthermore, the skills and experiences among local surgeons and cardiologists in the region are lacking (Burnham et al., 2012; Custer, 2009). Finally, both hospitals are also considered as teaching hospitals. Thus, the physicians in such hospitals have to cooperate with other physicians to improve their skills and enhance their ability to provide excellent medical services to citizens (KRG, 2007).

Given the focus of this study on the issue of cooperation among physicians in sharing information and skills in patient treatment, the population comprised 100 physicians. They included hospital managers, doctors, senior house officers, intervention cardiologists and cardiac surgeons. All of them were involved in care units related to a cardiac centre. These physicians were drawn from two aforementioned hospitals (Hospital A and Hospital B). The population profile is tabulated in Table 2.
The questionnaires were personally handed to the respondents. 100 questionnaires were distributed with $81 \%$ response rate questionnaires were fully completed and included for analysis after excluding incomplete questionnaires. 65 participants $(80 \%)$ were from the Hospital A and $16(20 \%)$ were from the Hospital B. Of the total, $68(84 \%)$ were male and $13(16 \%)$ were female. The academic qualifications of the respondents are as follows: $6(7.40 \%)$ had a Diploma, 39 (48.10\%) had a Bachelor's degree, 5 (18.50\%) had a Master's degree and $21(25.90 \%)$ had a $\mathrm{PhD}$ in medicine. The overall responses in this category showed that the majority of the physicians had a basic bachelor's degree instead of a Master's or PhD degree, implying a low number of professional physicians in the healthcare centers of Kurdistan region, especially cardiac centers, being studied.

In-depth interviews were conducted with 10 specialist physicians, including cardiac center managers, intervention cardiologists and cardiac surgeons from a subsample of the population for this study. In the Hospital A, six specialist physicians, including the manager of the cardiac center, were interviewed; meanwhile, in the Hospital B, four specialist physicians, including the manager, were interviewed. The in-depth interviews were crucial in the investigation of issues in a more in-depth manner that could not be studied in the research instrument of questionnaire.

Table 1. Hospital locations

\begin{tabular}{lll}
\hline The federal region & City & Hospital \\
\hline Kurdistan Region/Iraq & Duhok & Hospital A \\
& Erbil & Hospital B \\
\hline
\end{tabular}

Table 2. The population profile

\begin{tabular}{|c|c|c|c|c|}
\hline Hospital name & Hospital specialization & Physicians & Physicians number & Cardiac centre units \\
\hline Hospital A & $\begin{array}{l}\text { - General hospital } \\
\text { - Teaching hospital }\end{array}$ & $\begin{array}{l}\text { - Hospital manager } \\
\text { - Doctors } \\
\text { - Senior house officers } \\
\text { - intervention cardiologists } \\
\text { - cardiac surgeons }\end{array}$ & $\begin{array}{l}80 \text { physicians (10-15 intervention } \\
\text { cardiologists and cardiac surgeons) } \\
\text { *Note: This number of } \\
\text { physicians in change }\end{array}$ & $\begin{array}{l}\text { - Consultation } \\
\text { - Cardiac Catheterization } \\
\text { - Echo } \\
\text { - ECG } \\
\text { - Lab Investigations } \\
\text { - Exercise } \\
\text { - CCU } \\
\text { - Cardiac Surgery }\end{array}$ \\
\hline Hospital B & $\begin{array}{l}\text { - Cardiology hospital } \\
\text { - Teaching hospital }\end{array}$ & $\begin{array}{l}\text { - Hospital manager } \\
\text { - Senior house officers } \\
\text { - intervention cardiologists } \\
\text { - cardiac surgeons }\end{array}$ & $\begin{array}{l}20-30 \text { physicians } \\
\text { *Note: This number of } \\
\text { physicians in change }\end{array}$ & $\begin{array}{l}\text { - Emergency } \\
\text { - Consultation } \\
\text { - Cardiac Catheterization } \\
\text { - ECG - Echo } \\
\text { - Lab Investigations } \\
\text { - Exercise } \\
\text { - CCU } \\
\text { - Cardiac Surgery }\end{array}$ \\
\hline
\end{tabular}




\section{DATA ANALYSIS AND FINDINGS}

\subsection{The Current Levels of Cooperation among Physicians within the Hospital Environment}

Section 3 of the questionnaire was intended to determine the current levels of professional cooperation among physicians in sharing information and skills in patient treatment. The aformentioned section contained nine types of cooperation with responses provided on a five-point Likert scale. Respondents were asked to rate their opinion on the cooperation among them on a scale of 1 to 5 ( $1=$ no cooperation, $2=$ little cooperation, $3=$ some cooperation, $4=$ good cooperation and $5=$ very good cooperation) and nine types of cooperation among physicians were analyzed, with a mean rating of 1.994 indicating minimal cooperation (Table 3).

In Table 3, mixed responses were obtained from types 1 and 2 of cooperation, in which 56.8 and $86.4 \%$ indicated "no cooperation" and "little cooperation", respectively and 43.2 and $13.5 \%$ indicated "some cooperation" and "good cooperation", respectively. These results indicated that there was poor cooperation in the sharing of physicians' skills in the same and in different workplaces. However, these results also indicated that there was some cooperation and good cooperation. This diversity of responses was mainly due to the work process in the hospitals, almost all of which used the manual system. The doctors meet regularly to discuss patient-related matters, but such a meeting was valid only in the case of one selected hospital. For example, one of the expert physicians in the interviews said, "We have a meeting every week and we discuss the difficult cases and other activities". In the type 3 of cooperation, $86.4 \%$ of the physicians reported no cooperation and little cooperation in sharing their skills via a database for distributing information in the hospital. This previous rating of the respondents indicated that the hospital almost completely used the manual system in daily work. One proof is that a specialist physician of the Hospital A said, "In our work, we have paper forms to record our patients' information". However, in the same type of cooperation, $4.9,6.2$ and $2.5 \%$ of the respondents reported some cooperation, good cooperation and very good cooperation, respectively. This low rate of diversity was observed in the Hospital B, which has a simple computerized HIS. As one of the physicians in the interviews said, "In our centre, we have an intranet database system, but it is local, centralized and only for our patient records". Even though there is some cooperation in sharing patient information, majority of the respondents declared they had no or little cooperation on other types of cooperation as shown in Table 3.

Despite the presence of a few specialist physicians, majority of the interviewees said that there is a weak cooperation among physicians in sharing healthcare information. For example, one of the participants said, "There is poor cooperation among doctors because each doctor works independently and there is no system to capture and save the information of all activities in our hospital". This weak cooperation is largely a result of not having distributed information systems and inadequate information technology infrastructure supports.

\subsection{Factors Affecting Cooperation among Physicians within the Hospital Environment}

This study investigated the factors affecting cooperation among physicians with regard to the sharing of information and skills in patient treatment in the Iraqi hospital environment. Section 2 of the questionnaire was on the background information related to the HIS in hospitals. Some items of the aformentioned section indicated certain factors that influence cooperation among physicians in sharing information from the respondents' opinion (Table 4).

Table 4 shows that all physicians knew how to use computer-based systems and that they browsed through the Internet to improve their knowledge to provide good healthcare. Of the total number of respondents, 73 $(90.10 \%)$ said they used Internet healthcare information, but the information obtained was inaccurate in some cases (APFO, 2010; BBC, 2010; Team, 2010). Using the computer-based systems was not a problem to these physicians, but the main concern was the lack of reliable healthcare information in their HIS environment, as indicated by the following data: 60 respondents $(74.10 \%)$ said that they did not have computer-based HISs and 72 $(88.90 \%)$ said that there was no distributed HIS between their hospital units and other hospitals. As one of the interviewees said, "In our hospital, I think there is one database system in the statistics division; however, it is inadequate, deficient and almost not electronic". Moreover, 73 respondents $(90.10 \%)$ said that there was no available procedure to reduce medical errors, 71 respondents $(87.70 \%)$ indicated that there was no mechanism to determine the confidence level of surgeons and physicians and 79 respondents (97.50\%) stated that there was no unit in the hospital that helped improve patients' process activities and made the hospital a reliable $\mathrm{R} \& \mathrm{D}$ unit. 
Nawzat Sadiq Ahmed and Norizan Mohd Yasin / Journal of Computer Science 10 (5): 794-808, 2014

Table 3. Descriptive results of the level of Professional cooperation among physicians $(\mathrm{N}=81)$ (note: V. and Co. are abbreviations of very and cooperation, respectively)

\begin{tabular}{|c|c|c|c|}
\hline Type of cooperation & Responses & $(\%)$ & Mean \\
\hline \multirow[t]{4}{*}{ 1) Physicians sharing of skills in the same hospital } & No Co. & 19.8 & Mean $=2.36$ \\
\hline & Little Co. & 37.0 & Std. $=0.940$ \\
\hline & Some Co. & 30.9 & \\
\hline & Good Co. & 12.3 & \\
\hline \multirow{4}{*}{$\begin{array}{l}\text { 2) Physicians sharing of skills in } \\
\text { various hospitals in your town }\end{array}$} & No Co. & 42.0 & Mean $=1.77$ \\
\hline & Little Co. & 44.4 & Std. $=0.810$ \\
\hline & Some Co. & 8.6 & \\
\hline & Good Co. & 4.9 & \\
\hline \multirow{5}{*}{$\begin{array}{l}\text { 3) Physicians sharing of skills by means of a database for } \\
\text { distributing information among them in your hospital }\end{array}$} & No Co. & 45.7 & Mean $=1.79$ \\
\hline & Little Co. & 40.7 & Std. $=0.971$ \\
\hline & Some Co. Good Co. & 4.9 & \\
\hline & V. Good Co. & 6.2 & \\
\hline & & 2.5 & \\
\hline \multirow{5}{*}{$\begin{array}{l}\text { 4) Physicians sharing of skills through research } \\
\text { and development activities among hospitals }\end{array}$} & No Co. & 48.1 & Mean $=1.90$ \\
\hline & Little Co. & 29.6 & Std. $=1.136$ \\
\hline & Some Co. & 11.1 & \\
\hline & Good Co. & 6.2 & \\
\hline & V. Good Co. & 4.9 & \\
\hline \multirow{5}{*}{$\begin{array}{l}\text { 5) Physicians sharing of skills from different } \\
\text { hospitals in order to improve their skills }\end{array}$} & No Co. & 30.9 & Mean $=2.07$ \\
\hline & Little Co. & 50.6 & Std. $=1.116$ \\
\hline & Some Co. & 6.2 & \\
\hline & Good Co. & 4.9 & \\
\hline & V. Good Co. & 7.4 & \\
\hline \multirow{5}{*}{$\begin{array}{l}\text { 6) Physicians sharing of skills with regard to connecting } \\
\text { healthcare information systems among hospitals in order to } \\
\text { enhance the quality of healthcare services }\end{array}$} & No Co. & 28.4 & Mean $=2.11$ \\
\hline & Little Co. & 54.3 & Std. $=1.140$ \\
\hline & Some Co. Good Co. & 3.7 & \\
\hline & V. Good Co. & 4.9 & \\
\hline & & 8.6 & \\
\hline \multirow{5}{*}{$\begin{array}{l}\text { 7) Cooperation among physicians with regard to design } \\
\text { system for healthcare activities among hospitals }\end{array}$} & No Co. & 46.9 & Mean $=1.86$ \\
\hline & Little Co. & 38.3 & Std. $=1.148$ \\
\hline & Some Co. & 3.7 & \\
\hline & Good Co. & 3.7 & \\
\hline & V. Good Co. & 7.4 & \\
\hline 8) Physicians sharing of skills among different & No Co. & 33.3 & Mean $=2.04$ \\
\hline \multirow[t]{4}{*}{ hospitals in order to increase the use of human resources } & Little Co. & 44.4 & Std. $=1.054$ \\
\hline & Some Co. & 12.3 & \\
\hline & Good Co. & 4.9 & \\
\hline & V. Good Co. & 4.9 & \\
\hline \multirow{5}{*}{$\begin{array}{l}\text { 9) Cooperation among physicians with regard to distributing a new } \\
\text { activity happens in the system among them in real-time }\end{array}$} & No Co. & 33.3 & Mean $=2.05$ \\
\hline & Little Co. & 43.2 & Std. $=1.059$ \\
\hline & Some Co. & 13.6 & \\
\hline & Good Co. & 4.9 & \\
\hline & V. Good Co. & 4.9 & \\
\hline
\end{tabular}

Moreover, On the suggestions section of the questionnaire, the physicians were asked to give some reasons that affect the cooperation among them in terms of sharing of skills, most of the respondents answered that each physician worked independently and there was no electronic healthcare information system through which their activities were saved, monitored and distributed. This happened due to the fact that the healthcare organization system in Kurdistan region allows specialized doctors employ in the government hospitals and private clinics (Heshmati and Darwesh, 2007). In addition, most of them reported that there were weak activities of the $\mathrm{R} \& \mathrm{D}$ unit in their hospital. 
Table 4. Descriptive results of questions in the background information section of questionnaire $(\mathrm{N}=81)$

\begin{tabular}{|c|c|c|c|c|}
\hline Question & Res. & Freq. (\%) & Mean & Std. D. \\
\hline 1) Do you know how to use the & Yes & $81(100.0)$ & \multirow[t]{2}{*}{1.00} & \multirow[t]{2}{*}{0.000} \\
\hline computer-based systems? & No & $00(000.0)$ & & \\
\hline 2) Do you know how to & Yes & $81(100.0)$ & \multirow[t]{2}{*}{1.00} & \multirow[t]{2}{*}{0.000} \\
\hline use and surf in the internet? & No & $00(000.0)$ & & \\
\hline 3) Did you take any information about & Yes & $73(90.10)$ & \multirow[t]{2}{*}{1.10} & \multirow[t]{2}{*}{0.300} \\
\hline healthcare services from the internet? & No & $08(09.90)$ & & \\
\hline 4) Are there any healthcare information systems in your & Yes & $21(25.90)$ & \multirow[t]{2}{*}{1.74} & \multirow[t]{2}{*}{0.441} \\
\hline hospital about healthcare services? & No & $60(74.10)$ & & \\
\hline 5) Are there any healthcare information systems & Yes & $09(11.10)$ & \multirow[t]{2}{*}{1.89} & \multirow[t]{2}{*}{0.316} \\
\hline between different hospitals in your town? & No & $72(88.90)$ & & \\
\hline 6) Does the hospital in your town have a & Yes & $08(09.90)$ & \multirow[t]{2}{*}{1.90} & \multirow[t]{2}{*}{0.300} \\
\hline system for reducing medical errors? & No & $73(90.10)$ & & \\
\hline 7) Is there a system that shows the level of confidence in the & Yes & $10(12.30)$ & \multirow[t]{2}{*}{1.88} & \multirow[t]{2}{*}{0.331} \\
\hline results of operations in your hospital? & No & $71(87.70)$ & & \\
\hline 8) Do you think the hospitals in your town are trusted units? & Yes & $43(53.10)$ & \multirow[t]{2}{*}{1.47} & \multirow[t]{2}{*}{0.502} \\
\hline & No & $38(46.90)$ & & \\
\hline 9) Is there research and development unit in & Yes & $02(02.50)$ & \multirow[t]{2}{*}{1.98} & \multirow[t]{2}{*}{0.156} \\
\hline every hospital in your location? & No & $79(97.50)$ & & \\
\hline
\end{tabular}

Furthermore, majority of the physicians in the interview mentioned a lack of cooperation among them due to the absence of an electronic HIS, that most of the work was paper-based, that the $R \& D$ unit activities were weak and that there was no time for doctors to see the patients' medical history and share their experience with others. For instance, one of the interviewees said, "We don't have complete patient records and medical history because our system is mainly based on papers and the management has no interest in improving services such as developing a good information system." The same interviewee said, "The R\&D activities are weak; we have not progressed to reach the level of the advanced centers in the world. We are interested in working on this unit as soon as possible". Another interviewee said, "The time factor also affects our work because this centre is very busy. It has many patients and a limited number of doctors".

In summary, the results indicated that certain factors that were supposed to facilitate cooperation among physicians in sharing information and skills are weak due to: (1) a manual system of healthcare management is used, thus making paper-based information difficult to manage, control and share, (2) physicians work individually in patient treatment due to the time factor and the absence of an electronic HIS in their healthcare system environment, (3) The acquisition of new knowledge in real time via the manual system of healthcare in the same hospital and in different ones is difficult for physicians and (4) there are weak R\&D unit activities in the Iraqi hospital environment.

\subsection{R\&D Unit Activities}

This study determined how the R\&D unit activities affect cooperation among hospital physicians. Section 4 of the questionnaire was about the work of the R\&D unit in the hospital environment. The aformentioned section contained nine statements on the role of $R \& D$ activities in the hospital, with responses provided on a five-point Likert scale ( 1 = strongly disagree, $2=$ disagree, $3=$ neutral, $4=$ agree and $5=$ strongly agree). Respondents were asked to provide feedback on the role of $R \& D$ unit activities in the hospital. The summary of the responses is presented in Table 5. The mean rating of respondents, 4.210 , indicated that the role of the R\&D unit activities was crucial in improving the cooperation among physicians to enhance healthcare services.

In Table 5, 92.6\% of the respondents agreed and strongly agreed that the significant role of the R\&D unit in the hospital is to improve the cooperation among physicians in sharing their skills. Of the total number, 92.6\% also agreed and strongly agreed that this unit can enhance the healthcare services in the hospital environment. In addition, $97.5 \%$ of the respondents agreed and strongly agreed that the improvement of physician skills and the enhancement of healthcare services can result in more reliable services. Among the respondents, 79.0 and $92.6 \%$ agreed and strongly agreed that the hospitals contained decentralized and autonomous organizational units and that the connection between these similar autonomous units could produce better healthcare services in terms of quality, respectively. 
Table 5. Descriptive results of the work of research and development unit activities $(\mathrm{N}=81)$

Statement
cooperation among physicians' skills.
2) The research and development services in your hospital
have benefits to increase the quality of healthcare services.

3) The research and development unit makes the hospitals in your town more trusted units.

4) The hospitals contain decentralized and autonomous organizational units for healthcare services supporting, as a research and development units.

5) The connection between similar autonomous units (i.e., research and development units), from different hospitals increases the quality of healthcare services.

6) The integrated view of the research and development services system among hospitals is an efficient information system for researchers and physicians.

7) For weak research and development activities in your hospital, many physicians refer to web resources to help them in completing their research and patient treatments. 8) The research and development activities in the hospitals in your town depend on the paper-based system managed and controlled by the group of researchers (physicians).

9) The research and development activity in the hospital should circulate healthcare information simply and quickly among specialists to enhance the quality of healthcare services.

\begin{tabular}{|c|c|c|}
\hline Responses & $(\%)$ & Mean \\
\hline Neutral & 7.4 & $\mathrm{M}=4.44$ \\
\hline Agree & 40.7 & \\
\hline St. Agree & 51.9 & Std. $=0.632$ \\
\hline St. Disagree & 1.2 & $\mathrm{M}=4.27$ \\
\hline Disagree & 2.5 & \\
\hline Neutral & 3.7 & Std. $=0.758$ \\
\hline Agree & 53.1 & \\
\hline St. Agree & 39.5 & \\
\hline Neutral & 2.5 & $\mathrm{M}=4.52$ \\
\hline Agree & 43.2 & \\
\hline St. Agree & 54.3 & Std. $=0.550$ \\
\hline \multirow[t]{2}{*}{ St. Disagree } & 1.2 & $\mathrm{M}=3.98$ \\
\hline & 1.2 & \\
\hline Neutral & 18.5 & Std. $=0.758$ \\
\hline Agree & 56.8 & \\
\hline St. Agree & 22.2 & \\
\hline St. Disagree & 1.2 & $\mathrm{M}=4.28$ \\
\hline Neutral & 6.2 & \\
\hline Agree & 54.3 & Std. $=0.693$ \\
\hline St. Agree & 38.3 & \\
\hline St. Disagree & 1.2 & $\mathrm{M}=4.17$ \\
\hline Neutral & 9.9 & \\
\hline Agree & 58.0 & Std. $=0.703$ \\
\hline St. Agree & 30.9 & \\
\hline Neutral & 14.8 & $\mathrm{M}=4.10$ \\
\hline Agree & 60.5 & \\
\hline St. Agree & 24.7 & Std. $=0.625$ \\
\hline St. Disagree & 4.9 & $\mathrm{M}=3.62$ \\
\hline Disagree & 7.4 & \\
\hline Neutral & 29.6 & Std. $=1.056$ \\
\hline Agree & 37.0 & \\
\hline St. Agree & 21.0 & \\
\hline St. Disagree & 1.2 & $\mathrm{M}=4.51$ \\
\hline Disagree & 1.2 & \\
\hline Neutral & 1.2 & Std. $=0.709$ \\
\hline Agree & 38.3 & \\
\hline St. Agree & 58.0 & \\
\hline
\end{tabular}

A simple regression analysis was conducted to Thus, $85.2 \%$ of the respondents indicated that there was no system for R\&D activities in their hospital environment or a system that connects HISs. Consequently, the physicians conducted their research on the Web resources for additional information of patients' treatment. However, $58.0 \%$ of the respondents agreed and strongly agreed that most hospitals' activities use a paper-based system, which creates difficulty for the physicians in searching for particular information in a large volume of information stored on paper. Additionally, $96.3 \%$ of the respondents indicated that the best way to enhance healthcare services in hospitals is to have a mechanism that can rapidly distribute information among specialists. identify the best predictors of the dependent variable and show the proportion of variance in the dependent variable (cooperation among physicians) explained by R\&D unit activities. A direct method entry was used in the simple linear regression analyses. The standard regression with a direct method entry was used to measure the relationships among variables. The summary of the simple regression results is presented in Table 6-8. The results indicated that $75.2 \%$ of the variance in cooperation among physicians with regard to the sharing of information and skills in patient treatment was explained by $R \& D$ unit activities. The test statistic was significant at the 0.01 level $(F(1,79)=7.230 ; p=0.008)$. 
Table 6. Standard regression model summary

\begin{tabular}{lllll}
\hline Model & $\mathrm{R}$ & $\mathrm{R}^{2}$ & $\begin{array}{l}\text { Adjusted } \\
\mathrm{R} \text { Square }\end{array}$ & $\begin{array}{l}\text { Std. Error } \\
\text { of the estimate }\end{array}$ \\
\hline 1 & 0.867 & 0.752 & 0.715 & 17.948 \\
\hline
\end{tabular}

Table 7. ANOVA: Regression significance

\begin{tabular}{lcrcrl}
\hline Model & Sum of squares & Df & Mean square F & Sig. \\
\hline Regression & 285.669 & 1 & 285.659 & 7.23 & $0.008^{\mathrm{a}}$ \\
Residual & 4662.133 & 79 & 39.510 & & \\
Total & 4947.792 & 80 & & & \\
\hline
\end{tabular}

Table 8. Regression coefficients of standard regression model (Dependent variables: Cooperation; $\mathrm{N}=81 ; \mathrm{p}<0.01$ )

\begin{tabular}{|c|c|c|c|c|c|}
\hline \multirow[b]{2}{*}{ Model } & \multicolumn{2}{|c|}{ Unstandardized coefficients } & \multicolumn{3}{|c|}{ Standardized coefficients } \\
\hline & B & Std. Error & Beta & $\mathrm{T}$ & Sig. \\
\hline Constant & 1.972 & 0.574 & & 3.122 & 0.008 \\
\hline$R \& D$ & 1.549 & 0.576 & 0.24 & 2.689 & 0.008 \\
\hline
\end{tabular}

Majority of the physicians interviewed emphasized that the role of the R\&D unit was to facilitate verbal communication among physicians regarding patient information and treatment skills, updating the knowledge of physicians and providing the best treatment for patients. For instance, one of the physicians said, "The benefits of $R \& D$ unit activities include updating our knowledge and providing better treatment for patients by enabling us to see the results of any patient, which will give the patient a good management depending upon the results". Another said, "We have in this unit a weekly consultation meeting to discuss some difficult cases of our patients and methods of treatment".

In summary, the results indicated that the role of R\&D unit activities in improving cooperation among physicians and enhancing healthcare services in two government hospitals in Kurdistan was conclusive because the agreement ratings were strong. The implication is that the critical role of the activities in this unit is to improve cooperation among physicians in sharing their skills and to manage and control the hospital's activities in the patient treatment.

\section{DISCUSSION}

Currently, there is still lack of cooperation among physicians in sharing information and skills in the patients' treatment within the hospital environment in Kurdistan region of Iraq. This study indicate there was no and little cooperation among physicians with regard to the nine types of cooperation (with average mean = 1.994). Based upon the literature and findings of this study, this lack of cooperation among physicians is due to several significant factors. First, healthcare centers wish to maintain autonomy in their activities, especially in the healthcare system of Iraq due to its hospital-based. In addition, a flexible cooperative approach is not the norm in development of cooperative HISs environment. Many researchers in this area proposed centralized database model to share patient information among medical staff but such models are not flexible in its structure, difficult to manage and control of enormous data in complex healthcare systems and these models have make HISs less autonomy. Another important factor that hinders physicians' cooperation for many developing countries including Iraq is the use of manual system that make information stored on paper difficult to manage, control and share. Therefore, the absence of electronic HIS has a significant impact on cooperation level among physicians. Without a good system, new knowledge is difficult to acquire real-time as indicated by $88.90 \%$ respondents that there is no distributed HISs between hospital units and other hospitals in their environment. Physicians working individually in patient treatment due to the time factor and the absence of electronic HIS in their healthcare system environment also hinder cooperative initiatives. Finally, R\&D unit activities are found to be weak in Iraqi hospital environment as $97.50 \%$ respondents stated there was no unit in the hospital that helped improve process activities and make the hospital a reliable unit. Results of regression revealed that the relation between $R \& D$ unit activities and cooperation among physicians in sharing healthcare information was $\mathrm{r}=0.867$ and it was significant at $\mathrm{p}<0.01$ giving a positive correlation. Improvement of $R \& D$ unit activities will improve the cooperation among physicians in sharing information and their skills within Iraqi's hospital environment.

\section{CONCLUSION}

In conclusion, this study found that the cooperation among physicians in sharing information and skills in the patient treatment within Iraqi's hospital environment is weak due to the six factors: (1) healthcare centers wish to maintain autonomy, (2) a flexible cooperative approach is not the norm in the developing of cooperative HISs environment, (3) large amount of data difficult to manage and control in a manual system and centralized database system, (4) new knowledge is not acquired in real-time by the physicians within the hospital environment, (5) physicians work independently and (6) R\&D unit activities are weak within the hospital environment. Also, this study found 
that there is positive relation between $R \& D$ unit activities and cooperation among physicians.

There were a few limitations for this study. First, this research focused only on the cooperation among physicians in sharing healthcare information within selected hospitals in Kurdistan region of Iraq. Kurdistan region was chosen because it has a developing, safe and stable situation and has relatively well developed healthcare facilities compared to other areas in Iraq. Second, the selection of the sample focused on physicians who work in care units related to the cardiac centre in each hospital. Third, the cooperation focused on physician's skills in patient treatment.

Recommendation base on this study, the improvement of cooperation among physicians with regard to the sharing of information and their skills to enhance physicians' skills within same and between different hospitals, especially in Iraqi hospitals, needs to overcome the aforementioned six significant factors. First, the need for development of cooperative HISs environment should be adapted based on an open, autonomic, flexible and cooperative method to link system units to provide decentralized and autonomous cooperative HISs model among different hospitals. In addition, there need to be a mechanism to support exchange of productive information beside patient information, such as physician's skills in the patient treatment, among physicians in real time in order to improve their skills by acquiring new knowledge from each other. Finally, R\&D unit activities within the hospital environment can manage and control hospital activities and help improve medical care by sharing information among healthcare teams. Ideally, R\&D units affecting cooperation among physicians in sharing information and skills in patient treatment can be connected with similar R\&D units of other hospitals to improve cooperation among physicians and enhance healthcare services within different hospitals.

\section{ACKNOWLEDGEMENT}

The reachears would like to appreciate the role of General Directorate of Health in Duhok-Kurdistan Regional Government-Iraq and two managers from the selected hospitals for their facilities provided by them and to thank all participants in the survey done for this study. This work is supported by the Ministry of Higher Education in Kurdistan region of Iraq and the University of Malaya.

\section{REFERENCES}

Abdullah, R., M.H. Selamat, S. Sahibudin and R.A. Alias, 2005. A framework for knowledge management system implementation in collaborative environment for higher learning institution. J. Knowl. Manag. Pract.

Aknine, S. and H. Aknine, 1999. Contribution of a multiagent cooperation model in a hospital environment. Proceedings of the 3rd Annual conference on Autonomous Agents, May 1-5, ACM Press, Seattle, Washington, United States, pp: 406-407. DOI: 10.1145/301136.301270

Ali, A., I. Abdulsalam and A.M. Hasan, 2011. Iraq health information system: Review and assessment. Government of Iraq, World Health Organization.

Al-Khawlani, M.A.A., 2009. A Web-based Integrated Health Care Management System. Dissertation Thesis, University Malaya, Kuala Lumpur, pp: 164.

Al-Tae, A.M.A., 2009. Effectiveness of the health care staff's serial empowerment to enhance the stages of methodical six sigma: Analysis of facts and a model presentation on educational medical complex in Nenaveh. University of Mosul, Mosul, Iraq.

Alwan, A., 2004. Health in Iraq. The Current Situation, Our Vision for the Future and Areas of Work. Ministry of Health.

APFO, 2010. Finding Quality Health Information Online.

BBC, 2010. Web child health advice 'wrong'. BBC news.

Best, J.W. and J.V. Kahn, 2006. Research in education. Pearson Education Inc.

Bryman, A., 2008. Social Research Methods. 1st Edn., Oxford University Press, Oxford.

Burnham, G., S. Malik, A.S.D. Al-Shibli, A.R. Mahjoub and A.Q. Baqer et al., 2012. Understanding the impact of conflict on health services in Iraq: Information from 401 Iraqi refugee doctors in Jordan. Int. J. Health Plann. Manage., 27: e51-e64. DOI: $10.1002 / \mathrm{hpm} .1091$

Chiasson, M., M. Reddy, B. Kaplan and E. Davidson, 2007. Expanding multi-disciplinary approaches to healthcare information technologies: What does information systems offer medical informatics? Int. J. Med. Inform., 76: S89-S97. DOI: 10.1016/j.ijmedinf.2006.05.010 
Chiesa, V., 1996. Managing the internationalization of R\&D activities. Eng. Manage. IEEE Trans., 43: 723. DOI: $10.1109 / 17.491264$

Chiesa, V., Manzini, R., Pizzurno, E., 2004. The externalisation of R\&D activities and the growing market of product development services. R\&D Manage., 34: 65-75. DOI: 10.1111/j.14679310.2004.00323.x

Chiu, R., C. Chan and C. Chang, 2007. Distributed Healthcare Database Integration for Supporting Agile Decision Making. ICS.

Collins, S.A., S. Bakken, D.K. Vawdrey, E. Coiera and L. Currie, 2011. Model development for EHR interdisciplinary information exchange of ICU common goals. Int. J. Med. Inform., 80: e141-e149. DOI: 10.1016/j.ijmedinf.2010.09.009

Curry, L.A., I.M. Nembhard and E.H. Bradley, 2009. Qualitative and mixed methods provide unique contributions to outcomes research. Circulation, 119: 1442-1452. DOI: 10.1161/CIRCULATIONAHA.107.742775

Custer, G.M., 2009. Audit of Usaid/Iraq's Iraq Rapid Assistance Program (IRAP). Audit Report No. E267-09-005-P Office of Inspector General, Baghdad, Iraq.

Dembo, D., 2010. Unified Communication Systems, Enhancing Patient Care. Asia Hospital and Healthcare Management.

Fedele, F., 1995. Healthcare and Distributed Systems Technology. ANSAworks 95, Cambridge-UK.

Gaboury, I., M. Bujold, H. Boon and D. Moher, 2009. Interprofessional collaboration within Canadian integrative healthcare clinics: Key components. Soc. Sci. Med., 69: 707-715. DOI: 10.1016/j.socscimed.2009.05.048

Gotoh, T., T. Takayama, M. Ishiki and T. Ikeda, 2005. A support system to consult remote another doctor on assessment and/or medical treatment plan when a doctor has a patient not in his/her major. Proceedings of the International Enformatika Conference, (IEC' 05), pp: 221-224.

Hameed, S.A., A.H.A. Hashim, S.S.M. Sharifudeen, V. Meho and O.O. Khalifa, 2008. An efficient emergency, healthcare and medical information system. Int. J. Biometric Bioinform., 2: 1-9.

Heshmati, A. and M.N. Darwesh, 2007. A Proposal to Establish National Health Service in the Federal Region of Kurdistan. Hawler Institute for Economic and Policy Research, Hawler Policy Report(2).
Isa, A., 2008. KOMAR and Dr Zryan, visit Swedish Ministeries of Trading and foreign affairs. KOMAR-Kurdish Organization for Medical Research.

Kannampallil, T.G., G.F. Schauer, T. Cohen and V.L. Patel, 2011. Considering complexity in healthcare systems. J. Biomed. Inform., 44: 943-947. DOI: 10.1016/j.jbi.2011.06.006

Kirikova, M., 2009. Towards flexible information architecture for fractal information systems. Proceedings of the International Conference on Information, Process and Knowledge Management, Feb. 1-7, IEEE Xplore Press, Cancun, pp: 135-140. DOI: 10.1109/eKNOW.2009.25

Kopala, M. and L.A. Suzuki, 1999. Using Qualitative Methods in Psychology. 1st Edn., Sage Publications, Inc., ISBN-10: 0761910379, pp: 256.

KRG, 2007. Iraq's largest and best equipped cardiac care hospital opens in Kurdistan's capital. Erbil Kurd Net.

Kumar, C.S., C.V.G. Rao and A. Govardhan, 2012. A Framework for interoperable healthcare information systems. Int. J. Comput. Inform. Syst. Industrial Manag. Applicat., 4: 554-561.

Kuziemsky, C.E. and L. Varpio, 2011. A model of awareness to enhance our understanding of interprofessional collaborative care delivery and health information system design to support it. Int. J. Med. Inform., 80: e150-e160. DOI: 10.1016/j.ijmedinf.2011.01.009

Leary, M.R., 2011. Introduction to Behavioral Research Methods. 6th Edn., Pearson Education, Inc., ISBN10: 0205203981, pp: 448.

Li, K. and D. Yao, 2006. Cooperative work in heterogeneous medical information systems. Proceedings of the International Conference on Communications, Circuits and Systems Proceedings, Jun. 25-28, IEEE Xplore Press, Guilin, $\quad$ pp: 1821-1824. DOI: 10.1109/ICCCAS.2006.285027

Lu, X., 2005. Design and implementation of cooperative distributed dental medical information system. Proceedings of the 9th International Conference on Computer Supported Cooperative Work in Design, May 24-26, IEEE Xplore Press, pp: 799-803. DOI: 10.1109/CSCWD.2005.194287 
Mengiste, S.A., 2010. Analysing the Challenges of IS implementation in public health institutions of a developing country: The need for flexible strategies. J. Health Inform. Dev. Countries.

Miles, M.B. and A.M. Huberman, 1994. Qualitative Data Analysis: An Expanded Sourcebook. 2nd Edn., SAGE Publications, Inc., Thousand Oaks, CA., ISBN-10: 0803955405, pp: 352.

Morgan, D.L., 1998. Practical strategies for combining qualitative and quantitative methods: Applications to health research. Qualitative Health Res., 8: 362-376. DOI: 10.1177/104973239800800307

Morse, J.M., 1991. Approaches to qualitativequantitative methodological triangulation. Nurs. Res., 40: 120-123. DOI: 10.1097/00006199199103000-00014

Mun, J., M. Shin, K. Lee amd M. Jung, 2009. Manufacturing enterprise collaboration based on a goal-oriented fuzzy trust evaluation model in a virtual enterprise. Comput. Indus. Eng., 56: 888901. DOI: 10.1016/j.cie.2008.09.022

Nunnally, J., 1978. Psychometric Theory. 1st Edn., McGraw-Hill, New York.

Odeh, A., 1999. Measurement and Evaluation in the learning process. Dar-Al-Amal, Irbid-Jordan.

RCN, 2004. Promoting excellence in care through research and development: An RCN postition statement. Royal College of Nursing, London.

Reddy, M.C. and B.J. Jansen, 2008. A model for understanding collaborative information behavior in context: A study of two healthcare teams. Inform. Proc. Manage., 44: 256-273. DOI: 10.1016/j.ipm.2006.12.010

Reddy, M.C., P. Gorman and J. Bardram, 2011. Special issue on supporting collaboration in healthcare settings: The role of informatics. Int. J. Med. Inform., $\quad 80$ : 541-543. DOI: 10.1016/j.ijmedinf.2011.05.001

Ruxwana, N.L., M.E. Herselman and D.P. Conradie, 2010. ICT applications as e-health solutions in rural healthcare in the Eastern Cape Province of South Africa. Health Inform. Manage. J., 39: 1729.

Sadreddini, M.H., 2003. A framework for integrating distributed healthcare information systems. Iranian J. Inform. Sci. Technol., 1: 56-70.
Samuel, P.R.J., 2009. ICT integration in enhancing English language teaching and learning. University of Malaya, Kuala Lumpur.

Scandurra, I., M. Hagglund and S. Koch, 2008. From user needs to system specifications: Multidisciplinary thematic seminars as a collaborative design method for development of health information systems. J. Biomed. Inform., 41: 557569. DOI: $0.1016 /$ j.jbi.2008.01.012

Shahmoradi, L., M. Ahmadi and H. Haghani, 2007. Determining the most important evaluation indicators of Healthcare Information Systems (HCIS) in Iran. Health Inform. Manag. J., 36: 13-22.

Skilton, A., W.A. Gray, O. Allam and D. Morrey, 2007. A new approach to connecting information systems in healthcare. Data Manage. Data Everywhere, 4587: 168-171. DOI: 10.1007/978-3-540-733904_17

Skilton, A., W.A. Gray, O. Allam, D. Morry and H. Bailey, 2008. Role based access to support collaboration in healthcare. Shar. Data, Inform. Knowl., 5071: 177-180. DOI: 10.1007/978-3-54070504-8_16

Suter, W.N., 2011. Introduction to Educational Research: A Critical Thinking Approach. 2nd Edn., Sage Publications, Inc., ISBN-10: 1412995736, pp: 528.

Team, F.O.W., 2010. Health information on the web: Finding reliable information.

Teddlie, C. and F. Yu, 2007. Mixed methods sampling. J. Mixed Methods Res., 1: 77-100. DOI: 10.1177/2345678906292430

VanVactor, J.D., 2012. Collaborative leadership model in the management of health care. J. Bus. Res., 65: 555-561. DOI: 10.1016/j.jbusres.2011.02.021

Weir, C.R., K.W. Hammond, P.J. Embi, E.N. Efthimiadis and S.M. Thielke et al., 2011. An exploration of the impact of computerized patient documentation on clinical collaboration. Int. J. Med. Inform., 80: e62-e71. DOI: 10.1016/j.ijmedinf.2011.01.003

WHO, 2006. Country cooperation strategy for WHO and Iraq, 2005-2010. WHO, Regional Office for the Eastern Mediterranean, Cairo.

Xiao, L., B. Hu, M. Croitoru, P. Lewis and S. Dasmahapatra, 2010. A knowledgeable security model for distributed health information systems. Comput. Security, 29: 331-349. DOI: 10.1016/j.cose.2009.08.002 
Yang, H., K. Liu and R. Gan, 2009. An adaptive architecture for healthcare systems. Proceedings of the International Symposium on Web Information Systems and Applications, May 2224, Academy Publisher, Nanchang, P.R., China, pp: 250-253.

Yang, H., K. Liu and W. Li, 2010. Adaptive requirement-driven architecture for integrated healthcare systems. J. Comput., 5: 186-193.
Yang, T.H., Y.S. Sun and F. Lai, 2011. A scalable healthcare information system based on a serviceoriented architecture. J. Med. Syst., 35: 391-407.

Yang, Y., T. Qin, J. Jiang and Z. Liu, 2008. Distributed medical information system for chronic viral hepatitis. Proceedings of the International Symposium on Information Science and Engineering, Dec. 20-22, IEEE Xplore Press, pp: 559-562. DOI: 10.1109/ISISE.2008.9 